\title{
DESIGN CONCEPT OF A KINETIC FORM-ACTIVE HYBRID ENVELOPE STRUCTURE
}

\author{
M. C. PHOCAS, O. KONTOVOURKIS \& N. NICOLAOU \\ Department of Architecture, Faculty of Engineering, University of Cyprus, Nicosia, Cyprus.
}

\begin{abstract}
In architecture and specifically in the design of structures, natural systems are of particular interest as far as their principle integral characteristic is concerned, that of a multi-layered, finely tuned and differentiated combination of their components, leading to an optimization and autonomous adaptability with regard to varying external conditions. At the same time, the development of contemporary adaptable lightweight structures takes place on the basis of tensegrity, scissor mechanisms or primary members with predominant bending deformability. Driven by the principle integral characteristic of natural systems, the design concept of a kinetic hybrid structure for a building membranes' envelope is presented in the current paper. The primary structure is composed of scissor compression and bending-active members interconnected in series through continuous tension-only members with closed circuit. The transformability of the system case example is presented in an initial configuration and five transformation states that correspond to respective transformation states of the membranes' envelope. The integral composition of the kinetic hybrid structure is described with its configuration and parametric associative design. A preliminary investigation of the system's horizontal load-bearing behaviour throughout its transformation pathway follows a discussion on the motion planning of the structure. The latter builds on issues of the integrative development of the static and kinematic system, as well as minimization of external energy consumption for obtaining different operational configuration states.
\end{abstract}

Keywords: Bending-active members, hybrid systems, kinetic systems, scissor members, tensegrity structures.

\section{INTRODUCTION}

Related to the design of material efficient structures in terms of self-weight minimization and adequate stiffness and strength are the philosophical manuscripts 'Two New Sciences' by Galileo, where the meaning of mechanics was addressed to and especially the way that the proportions of a structure should change while this would be increased in scale [1]. Having compared his philosophical thought with the skeleton of biological organisms, he noted that the amount and function of a living organism do not relate to its skeleton. He related the overall size of animals to the stiffness and strength of their bones, as well as self-weight. 'From what has already been demonstrated, you can plainly see the impossibility of increasing the size of structures to vast dimensions either in art or in nature; ... so also it would be impossible to built up the bony structures of men, horses, or other animals so as to hold together and perform their normal functions, if these animals were to be increased enormously in height; for this increase in height can be accomplished only by employing a material, which is harder and stronger than usual, or by enlarging the size of the bones, thus changing their shape. ...Another principle, ..., which enables animals to vast size to support themselves and to move about as well as smaller animals do, ..., may be secured either by increasing the strength of the bones and other parts intended to carry not only their weight but also the superincumbent load; or, keeping the proportions of the bony structure constant, the skeleton will hold together in the same manner or even more easily, provided one diminishes, in the proper proportion the weight of the bony material, of the flesh and of anything else which the skeleton has to carry'. The typological development of structures with the mechanical properties of high-strength construction materials verify Galileos finding.

Biology is of particular interest, since it provides not only isolated phenomena in the design of structures but also new technical and methodological strategies. An important characteristic of natural systems is the integral, multi-layered, finely tuned and differentiated combination of basic 
components that lead to structures with multiple networked functions [2]. Natural structures consist of only a few basic components that are geometrically, physically and chemically differentiated. Besides optimization principles for prevailing constant external loading and functional conditions, natural structures provide principles for autonomous adaptation to time-varying external conditions. Related to the integrative development of systems with integrated kinematics is the organic theory described in [3].

In the context of contemporary constructions, the interactive relation of society, technology and architecture expanded the area of research, design and application of static systems aiming at transformability and adaptability. William Zuk and Roger H. Clark demonstrated the necessity for an architecture that is not static; instead it has the ability to adapt in time changes through systems with embedded kinetic mechanisms [4]. Kinetic architecture aims at the development of timely adaptable systems as to differing external loading, functional and environmental conditions and leads to buildings and components with variable mobility, or geometry. The latter is directly related to the properties of the integrative parts of the building, i.e. the structure and the building envelope. In this aspect, Buckminster Fuller favoured through 'Ephemeralization' reduction of material [5]. Robert Kronenburg illustrated the advantage of such systems in that, buildings that use fewer resources and adapt efficiently to complex site and programmatic requirements are particularly relevant to an industry, becoming increasingly aware of its environmental responsibilities [6].

In structural terms, minimum self-weight is directly related with aspects of structural modularity, in limiting the complexity of the system and supporting constructability, connectivity, in producing a complete structural system on modular basis, loading, in providing feedback about load transmission with changes in stiffness, and shape, in accurately testing the geometrical shape limits of the structural system. In this respect of special interest are tensegrity structures, i.e. self-stressed systems composed of tension and compression members, proposed for various applications including shelters and domes [7-10]. Tensegrity structures combine parts mutually supportive in such a way that the compression members do not touch one another but press outwardly against nodal points in the tension network to form firm, triangulated, prestressed tension and compression units [11, 12]. Form finding methods for tensegrity structures with regular and irregular shapes have been investigated in [13-16]. Furthermore, it is suggested that discontinuous compression, as in classical tensegrity systems, is not necessary and that more efficient structures can be achieved, if compression elements are allowed to join $[17,18]$. The development of double-layered frameworks composed of several basic tensegrity modules is presented in $[19,20]$, and cable-strut systems as an extension to tensegrities in [21-23].

Kinetic systems, primarily in terms of deployable structures, have been mainly studied during the last 25 years [24]. Deployable tensegrity structures may be transformed from a closed configuration to a predetermined expanded form, in which they are stable and can carry loads [25], through alteration of the compression or tension members' length, with only small quantities of energy needed due to their kinematic indeterminacy $[26,27]$. The main difficulty of the former method is that the cable often creates an inextricable tangle in the folded configuration, thus unfolding the system is often opposed. The latter rather proved to be a usable deployment method [28]. Relevant studies on the analysis of the deployment mechanisms, folding concepts and shape control based on stress analysis are included in [29-32]. Planar and spatial scissor-hinge elements comprise further common types of deployable structures with the ability to expand in a horizontal or in both horizontal and vertical direction [33-35]. While such structural elements need additional stabilizing members like cables or other locking devices, self-stable structures can be achieved with the application of special geometrical configurations through additional inner scissor-like-elements. A considerable advance in the design of such systems was made with the development of the simple angulated element and 
its geometrical principles [36, 37]. Nevertheless, both aforementioned deployable structure types do not constitute real form flexibility, since they do not convert to more than two different geometries of an open and closed state, i.e. they are not capable of achieving multiple shapes without changing the overall system's geometrical size and boundaries. In providing permanent structural transformability, a novel planar and spatial scissor-hinge mechanism is proposed in [38, 39].

The development of lightweight structures to obtain kinetic capabilities is primarily based on, respectively, articulated joints and embedded mechanical actuators. The essential characteristics of the systems are the controllable stiffness and lightweight [40]. Control techniques have been formulated that use minimal energy optimization in [41] and a closed mathematical formulation for the simulation of active tensegrity structures has been proposed in [42]. The feasibility of an adjustable tensegrity structure in simulations and full-scale prototype testing has been investigated in [43, 44]. A further example in this direction is the adjustable tensegrity shell building envelope presented in [45]. The transformability of the aluminium structure is achieved through application of mechanical actuators as pneumatic muscles at the place of compression members. Although the structure is designed to use a small number of components to achieve maximum shape adjustments, such a hard mechanical approach requires often designers to deal with high-energy costs and complex mechanisms and it often produces brittle and vulnerable kinetic systems.

Elastic kinematics as found in complex plant movements may act as role models for the development of new bio-inspired adaptable systems. Compared with technical systems, adaptable structures in nature replace local hinges by elastic deformations of their members and thus distribute the acting forces over a wider area in which bending takes place. This alternative approach renders the possibility to form complex single- or double-curved primary structures from straight or planar members. Sufficiently thin component thickness thereby allows for small bending radii and thus results in low bending stresses. Structural rigidity can be either increased by the combination of bending and tension prestress stored within individual elements, or by coupling of multiple elements to a hybrid system. In principle, hybrid systems are defined through linkage of different components in parallel and/or in series that are combined to resist forces by developing a specific mechanical behaviour due to their different resisting nature [46]. The potential of hybrid systems lays in the synergetic possibilities emanating from exploiting the systems' disparities: reciprocal compensation of critical stresses, system-transgressing multiple functions of individual components and increase in rigidity through opposite systems deflection [47]. The use of bending principles in hybrid systems enables not only initial complex geometries and their subsequent stabilization through additional prestress but also the capability of the members to undergo reversible deformations [48].

The utilization of bending-active systems has been demonstrated with a pavilion prototype construction at the University of Stuttgart in 2010, with birch plywood strips [49, 50]. In a kinematics context, the biomimetic principle of the valvular pollination mechanism in the Strelizia reginae flowers led to the prototype Flectofin that was applied for the shading system of the Biomimetic Media Façade for the Thematic Pavilion at Expo 2012 in Yeosu, South Korea [2, 51]. In principle, the backbone element of the flower is made of a flat section that is attached perpendicularly to the fin, a thin shell element. The sideways bending of the fin is a failure mode initiated by torsional buckling when bending of the backbone develops. As a result a recurved surface is formed in the fin, which provides the entire system with higher stiffness [52]. Following this kinematic principle, the building facade is made of slightly curved plates of glass fibre reinforced polymers supported by two hinged corners at the top and the bottom. In the other two corners, a small compressive force is applied by an actuator in the plane of the lamella, which leads to a controlled buckling. Thus, the structural effect responsible for the members' kinematics is initiated by lateral torsional buckling and continues as non-symmetrical bending mode. Further experimental kinetic envelopes for the 
investigation of elastic modular systems using passive and active form changing materials, such as silicon rubber and shape memory alloy, are discussed in [53].

A similar soft mechanical approach for the optimization of structures with regard to varying external loading conditions has been followed with the design of an actively controlled prototype bridge model at the Institute for Lightweight Structures and Conceptual Design at the University of Stuttgart [54]. Within the primary lamella structure, embedded actuators induce reciprocal bending deformations in areas of supplemental external loading resulting from a travelling load. Thus, adaptive systems could in principle be designed to reduce the structural deformation of specific bending-active members, so that an infinitely rigid system can be simulated on the long run. As a final example, the hybrid prototype structure consists of strips of three polyethylene terephthalate glycol layers that are interconnected by struts with variable length [55]. Modification of the struts length induces respective changes in the structure's curvature.

The design concept of the kinetic envelope structure presented in the current paper reflexively addresses the above-mentioned considerations with regard to lightweight structures, the natural systems inspired integrated development of the structural components and the synergy in the system's static and kinetic operability. In this frame, the typological principle of tensegrity structures with continuous compression members is applied in the development of a hybrid system with differentiated articulation of the compression members. The proposed structure consists of primary lamellas members of fibre composite material of high elasticity and tensile strength positioned in the weak axis to allow for adaptability and reversible elasticity. The bending-active members are linked in series to scissor units of pairs of compression members through cables with closed circuit. The cables have a dual function: to stabilize the primary members in each configuration operability state, i.e. they are responsible for the load-bearing behaviour of the hybrid structure under external loading and functional requirements, and to provide the system with controlled transformability for obtaining different configuration states. This is achieved through alteration of the cables' length by an actuator fixed at one of the cables' connection points and the application of rotating shafts with electromagnetic brakes at the joints. In summary, the most important advantage of the proposed structure over conventional kinetic lightweight structures is its form flexibility, meaning that it can adapt its shape according to the functional needs of the building envelope, as to the changing environmental conditions or architectural requirements. With regard to the actual development of the design concept, this implies an integrated iterative process that moves repeatedly between the respective related phases of configuration, construction, geometrical design, preliminary horizontal load-bearing behaviour analysis and planning of the system's kinematics as presented in the next sections.

\section{KINETIC HYBRID ENVELOPE STRUCTURE}

The design project proposes an adaptable membranes' envelope, whereas its transformation pathway is initially defined through a parametric associative design investigation of the system in relation to possible users input and environmental stimuli. The envelope acts as an architectural technological filter between the external- and internal-built environment and regulates heat, natural lighting and ventilation [56]. The system is envisaged to serve the rehabilitation and revitalization of old industrial- and urban built environments, respectively (Fig. 1). Through respective applications of the prototype, properties of response, adaptation and interaction between the users and the environment can be registered.

The envelope consists of two types of interactively transformable membranes of different physical properties (Fig. 2). Initially, the primary membranes, linearly supported by bending-active members, are stretched on the vertical and horizontal façade planes. The secondary membranes, linearly 

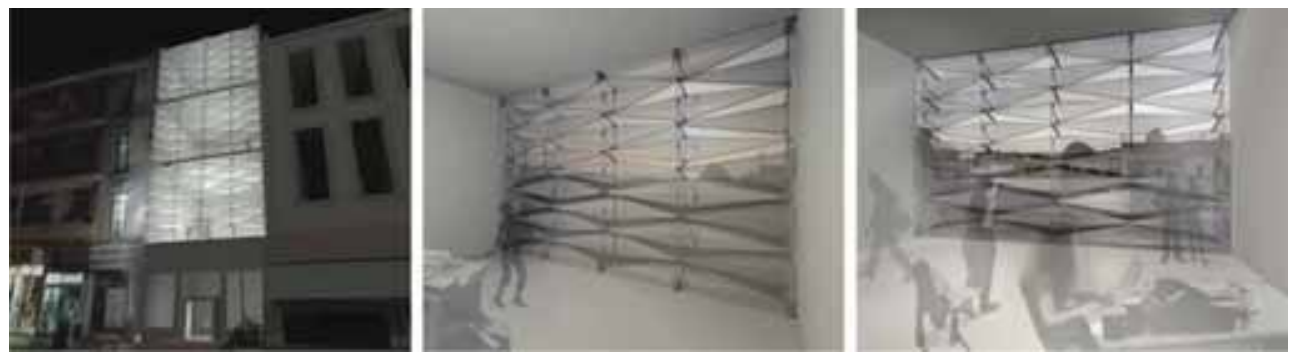

Figure 1: Adaptable façade prototype application study within the city core of Nicosia for the building premises of the Department of Architecture of the University of Cyprus.

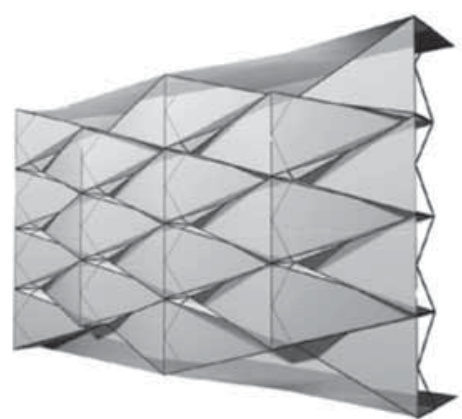

(a)

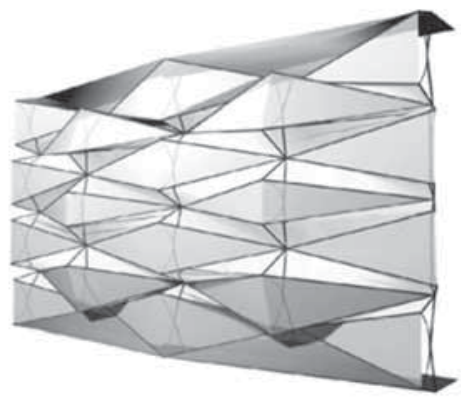

(b)

Figure 2: Envelope structure: (a) initial (closed) configuration state and (b) target (open) transformation state.

supported by compression members forming scissor mechanisms, are folded horizontally between the primary membranes. This mode supports the building operation in periods of high temperatures. When the primary membranes with lower transparency are folded in the vertical axis to form curved surfaces with decreased parabolic vertical radii, the secondary membranes open up towards a vertical position. In this stage, the corresponding semi-transparent skin increases and indirect natural light penetrates the interior. This mode supports the building operation in periods of low temperatures. Natural ventilation is enabled through a separate mechanism that regulates the porous skin of the secondary membranes (Fig. 3). The rails of the secondary membranes, fixed to the primary compression members, consist of shape memory alloy springs that expand in length by as much $8 \%$, when heat is applied via electricity, providing out of plane rotations of the members for the respective façade openings.

The primary structure is positioned alternately with overall lengths of 3.48 and $4.64 \mathrm{~m}$. It consists, respectively, of four and three vertical bending-active members interconnected through scissor compression members and a continuous cable with closed circuit (Fig. 4). In the initial configuration state, the bending-active members have an axial length of $1.16 \mathrm{~m}$ each and the scissor compression members are in closed, horizontal position. The primary cables are connected to the compression members' joints and the bending-active members at middle distances through rotating shafts equipped with electromagnetic brakes to act as static joints within each structural configuration (Fig. 5a). In the horizontal direction, the primary structure is positioned at distances of $2.0 \mathrm{~m}$, alternately as to the units sequence. The bending-active members consist of glass fibre reinforced polymer flat sections of $20 \mathrm{~mm} \times 90 \mathrm{~mm}\left(\mathrm{E}=2.6 \times 10^{4} \mathrm{kN} / \mathrm{cm}^{2}\right)$, the scissor compression members, of carbon 


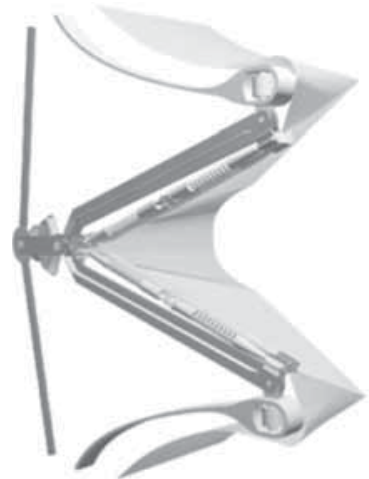

(a)

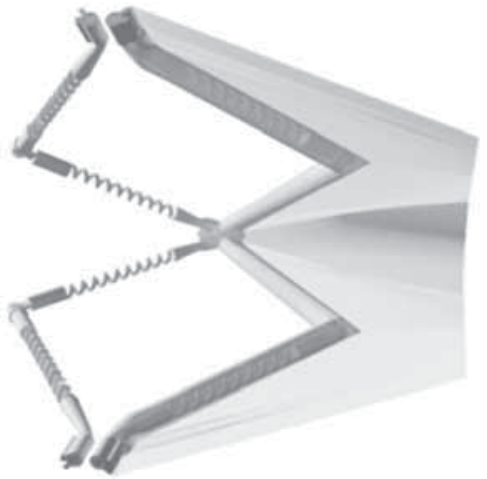

(b)

Figure 3: Air ventilation mechanism of secondary membrane: (a) closed porous state and (b) open porous state.

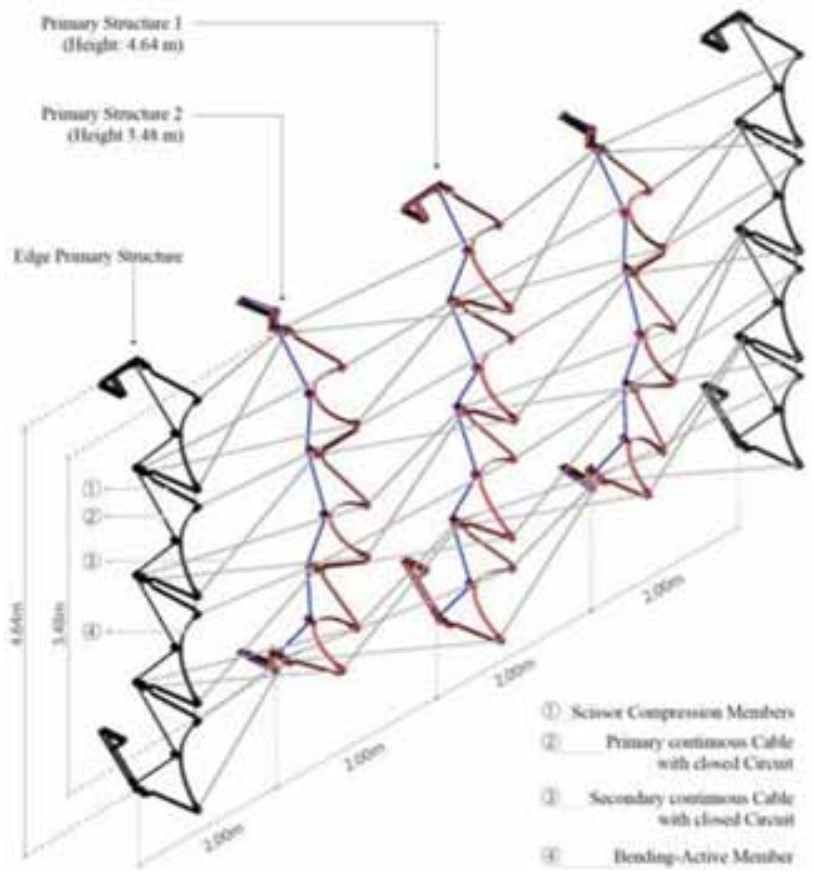

Figure 4: Structure's typology.

fibre reinforced polymer cross sections of $60 \mathrm{~mm} \times 50 \mathrm{~mm} \times 25 \mathrm{~mm}\left(\mathrm{E}=4.18 \times 10^{4} \mathrm{kN} / \mathrm{cm}^{2}\right)$. The primary cables have section diameter of $40 \mathrm{~mm}\left(\mathrm{E}=1.6 \times 10^{4} \mathrm{kN} / \mathrm{cm}^{2}, \mathrm{f}_{\mathrm{e}}=140 \mathrm{kN} / \mathrm{cm}^{2}\right)$. The slabs serve for the fixed supports of the primary structure (Fig. 5b). The structure may adapt to different floor heights through respective initial curvature of its elastic primary elements. 


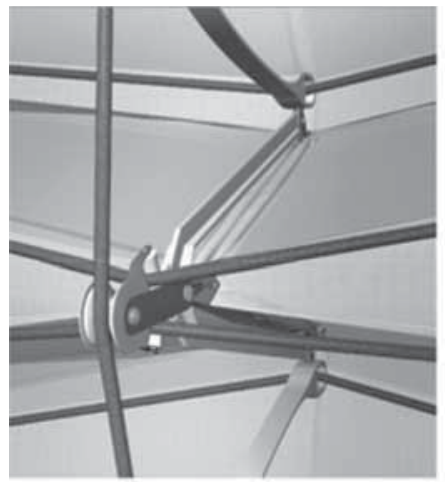

(a)

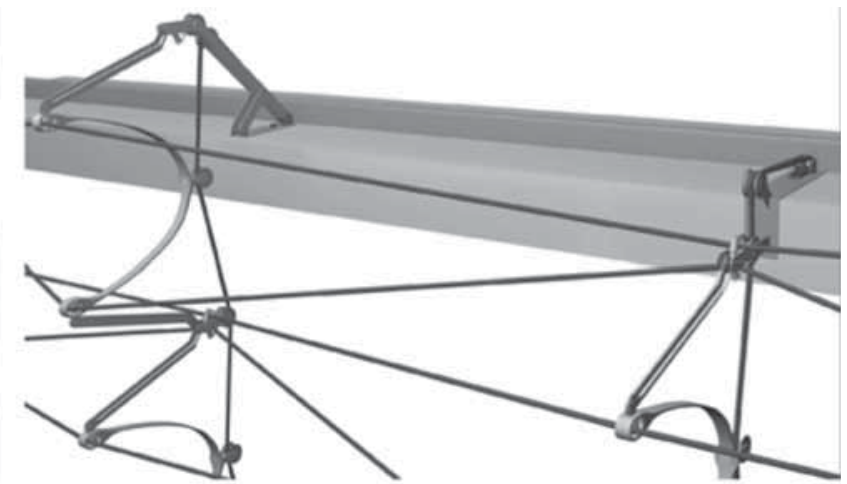

(b)

Figure 5: Structural connection principles: (a) primary cable to scissor compression members and (b) primary structure supports.

In the horizontal direction secondary cables of $55 \mathrm{~mm}$ diameter $\left(\mathrm{E}=1.6 \times 10^{4} \mathrm{kN} / \mathrm{cm}^{2}, \mathrm{f}_{\mathrm{e}}=140\right.$ $\mathrm{kN} / \mathrm{cm}^{2}$ ) connect at the joints of the vertical elements, e.g. adjacent joints of bending-active and compression members to primary cables. In this way, a tensile net is formed for the required in plane stability of the structure. The secondary cables are connected at the joints through rotating shafts with electromagnetic brakes; an interaction between adjacent units and consequently torsional effects on the primary members is kept minimum. The edge primary structures have constant geometrical characteristics and serve as rigid structural planes for the anchorage of the tensile net.

The bending-active members that support the primary membranes change their curvature through modification of the primary cables length and induce a respective motion of the adjacent scissor compression members that are responsible for the transformability of the secondary membrane. Reduction of the primary cables length induces deformations to the bending-active members, which in turn cause in-plane outwards rotation of the scissor compression members. The reverse movement for inwards rotation of the compression members is enabled through increase of the cables length and release of the corresponding mechanical energy accumulated in the bending-active members.

In its initial configuration state, i.e. ideally bending-active members in vertical and scissor units in closed position, the axial depth of the primary structure in the perpendicular plane direction amounts to $57 \mathrm{~cm}$. In the target transformation state, the parabolic curvature radii of the bending-active members amount to 40.75 and $34.61 \mathrm{~cm}$ and the opening angle of the scissor units, $48.46^{\circ}$ (Fig. 6). In the latter state, the axial depth of the primary structure at mid-span decreases to $51.98 \mathrm{~cm}$ (Table 1). During the transformation process, the joints of the primary members are subjected to horizontal displacements in the perpendicular plane direction (Fig. 7). A decrease of the vertical curvature radii of the bending-active members shifts the middle connection joint to the primary cable in outwards direction to the curvature. Respectively during the opening up process of the scissor units, the connection joints of the compression members are shifted inwards to the curvature. This effect is attributed to the flexibility of the form-active structure; the displacement of the bending-active members' middle joints supports the opening up process of the scissor units during the transformation process, although at the same time the opposite displacement of the compression members' joints decreases, respectively, the maximum possible opening of the units. Furthermore, by selecting fixed connection joints of the scissor compression members, i.e. preventing horizontal displacements in the perpendicular plane direction, non-symmetrical transformations of the structure would be feasible. In the simulation studies, the membranes were considered to be flexible enough to 


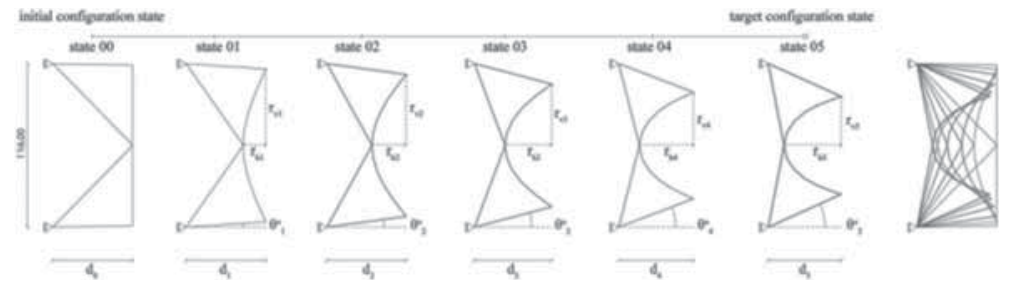

Figure 6: Bending-active members' geometrical configurations in initial configuration and transformation states $1-5$.

Table 1: Unit's transformations in two-dimensional geometrical analysis.

\begin{tabular}{lrrrrrr}
\hline & \multicolumn{7}{c}{ State } \\
\cline { 2 - 7 } Unit's parameters $\left(\mathrm{cm},{ }^{\circ}\right)$ & \multicolumn{1}{c}{0} & \multicolumn{1}{c}{1} & \multicolumn{1}{c}{2} & \multicolumn{1}{c}{3} & \multicolumn{1}{c}{4} \\
\hline $\mathrm{d}$ & 57.00 & 56.88 & 56.49 & 55.12 & 53.29 & 51.98 \\
$\mathrm{r}_{\mathrm{v}}$ & 57.00 & 54.20 & 50.34 & 43.43 & 37.76 & 34.61 \\
$\mathrm{r}_{\mathrm{h}}$ & 0.00 & 16.16 & 24.43 & 33.47 & 38.56 & 40.75 \\
$\Theta$ & $\sim 0$ & 3.82 & 7.72 & 14.75 & 20.80 & 24.23 \\
$\mathrm{l}_{\mathrm{c}}$ & 162.64 & 141.17 & 132.54 & 123.82 & 119.68 & 118.15 \\
\hline
\end{tabular}

accommodate the movement of the primary structure without having any interaction on the transformation process of the primary members.

\subsection{Parametric associative design}

The system's initial geometrical configuration and transformation states were digitally defined through parametric associative design logic. In this stage of investigation, the parametric design software Grasshopper and the live physics software Kangaroo (plug-in for Rhino and plug-in for Grasshopper, respectively) were used. In attempting to find close relations with the physical behaviour of the system, this was studied by taking into consideration the physical properties of the structural members, including the bending elasticity of GFRP lamellas, the axial stiffness of the compression members and the elastic tensile strength of the cables. The structure was parametrically, physically and associatively related to its components by applying physical behaviour according to the desirable behavioural goals. In this way, the overall geometrical behaviour of the system was studied at the level of the units with two supports, the primary structures with four units in series and two supports and the spatial system (Figs 6 and 7). Due to the flexibility of the components system in obtaining any equilibrium state, the three investigation levels yield respective geometrical differences according to the resulting curvature of the bending-active members and the opening angle of the scissor compression members. As a result, heterogeneity in the opening angles of the scissors is observed in every transformation state of the spatial system. For the geometrical definition from unit to primary structure and system level, only the central scissor opening is geometrically controlled in each transformation state, as described by the respective parameter values in Table 1 .

At the unit level, the investigation of the physical behaviour simulation process has been organized in three basic discrete categories according to the type of forces and the behavioural rules 


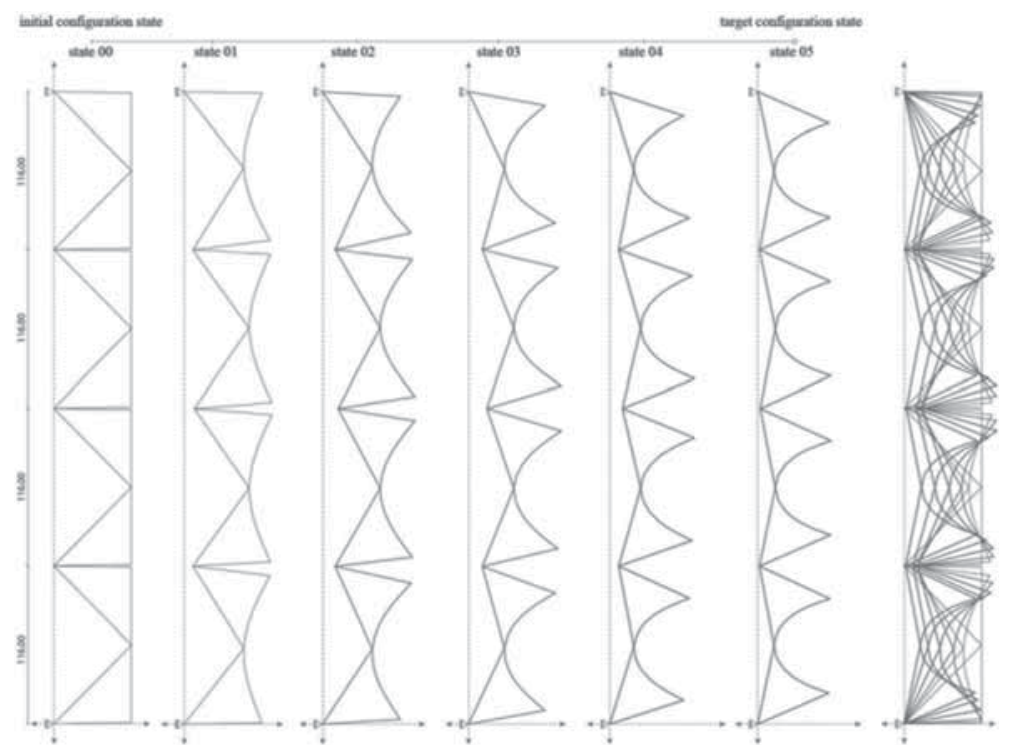

Figure 7: Primary structure's geometrical configurations in initial configuration and transformation states $1-5$.

applied to the members: bending, compression and tension. Each member carried its own behaviour characteristics primarily at the unit level, generating individual behaviours at the primary structure level, and their resultant forces generate the overall system behaviour. The geometrical configurations produced in the parametric associative design were transferred for preliminary structural analysis purposes to the Finite-Element programme SAP2000 through the software GeoGym (plugin for Grasshopper).

\subsubsection{Bending behaviour}

Structural bending behaviour is virtually simulated over the deviation of any set of three consecutive points of the discretized members from the straight line [57]. In the current investigation, the members' linear shape was parametrically divided into segments and points. The divisions and specifically the points of the members vary according to the required accuracy in physical behaviour. In this case, external action was physically described and controlled parametrically by specifying a point in the middle of each bending-active member. The respective members bending behaviour develops when the distance between the middle point on the bending-active member and the point on the vertical axis of the structure is parametrically modified. This represents also the actual actuators operation principle.

\subsubsection{Compression and tension behaviour}

The axial members were physically simulated by applying spring behaviour on the basis of Hooke's Law of elastic stress-strain behaviour $[58,59]$. Spring behaviour is defined through a number of inputs that can be parametrically modified influencing thus the members' behaviour in compression and tension. Specifically, in a spring component the input 'rest length' can be found, which influences the members length and hence its behaviour. If the rest length is equal to the start length (another input in the spring component), then the member is considered to be a compression member. 
In the current investigation, such behaviour was applied to the scissor compression members. These were geometrically connected with the bending-active members providing an overall behaviour that involved compression and bending. The simulation of the bending-active members behaviour and the rotation of the compression members connected to the primary cables with closed circuit verified in parallel the ability of the system to be stabilized due to a combination of bending and compression. If the rest length reaches the dimension of the start length (achieved by multiplying the start length with a number from 0 to 1 ), then the member is under tension. Such behaviour has been applied and simulated to all tension-only members of the system. This is reflected by a gradual relaxation of the model reaching its equilibrium position in any transformation state that was influenced by the geometrical and physical modification parameters.

\subsection{System behaviour}

A typical geometry was assigned for the ideal structural model as described in the previous section. The structural system consists of the edge primary structures of $4.64 \mathrm{~m}$ length, a middle primary structure of the same length and two primary structures of $3.48 \mathrm{~m}$ length positioned in-between at relative horizontal axial distances of $2.0 \mathrm{~m}$. In all cases examined, e.g. in the initial configuration and five transformation states, the edge primary structures were considered of constant geometry, corresponding to the geometrical characteristics of transformation state 2, with additional compression members of high stiffness to ensure constant relative inclinations of the scissor compression members (Fig. 8). A diaphragm constraint was considered for the supports of the edge structures in the perpendicular plane direction accounting for respective supports provided by inner shear walls for example. In addition, the slabs support all upper and lower compression members over diagonals of high stiffness. No relative displacements of the system supports have been considered in this preliminary analysis that would account for relative storey displacements. The dimensioning of the members was based on Eurocode 3 having assumed the self-weight of the structure, of the membranes with $0.75 \mathrm{kN} / \mathrm{m}$ and a static horizontal wind load of $1 \mathrm{kN} / \mathrm{m}^{2}$ (Fig. 9). The sections of the members are given in Section 2. A preliminary horizontal system's behaviour has been obtained following static nonlinear analysis to represent the behaviour of tension-only bracings modelled as frame objects with zero compression limits. No prestress has been assigned to the tension-only members for the load case investigated, in order to account for the actual kinematics of the system. The maximum absolute values of the internal axial forces, $\mathrm{N}$, and bending moments, $\mathrm{M}_{3-3}$, as well as the maximum joints' displacements, $\mathrm{U}_{1-1}$ and $\mathrm{U}_{3-3}$, in the initial configuration and the five transformation states of the system under horizontal loading, are included in Table 2.

A direct comparison of the maximum response values in all geometrical cases provides an insight with regard to the horizontal behaviour of the flexible hybrid system. As far as the maximum axial forces of the scissor compression members are concerned, these decrease from the initial configuration to the first transformation state by $62.1 \%$ and from then on the maximum value remains essentially constant. The maximum tension force of the vertical bracing increases substantially from the initial configuration to the first transformation state, by $677.85 \%$, and from then on it remains again practically constant. A different response behaviour is registered with regard to the maximum tension force of the secondary bracing. This decreases rapidly in the first transformation state by $68.01 \%$ and by further $72.22 \%$ in the fourth transformation state compared with the first one. In the target transformation state, it increases by $150.06 \%$ compared with the previous one. A direct comparison of the maximum tension forces of the bracings proves the significant contribution of the secondary bracing in the horizontal load-bearing behaviour of the system, especially in its initial configuration state, whereas the respective maximum tension force amounts to $1635.36 \%$ of the 

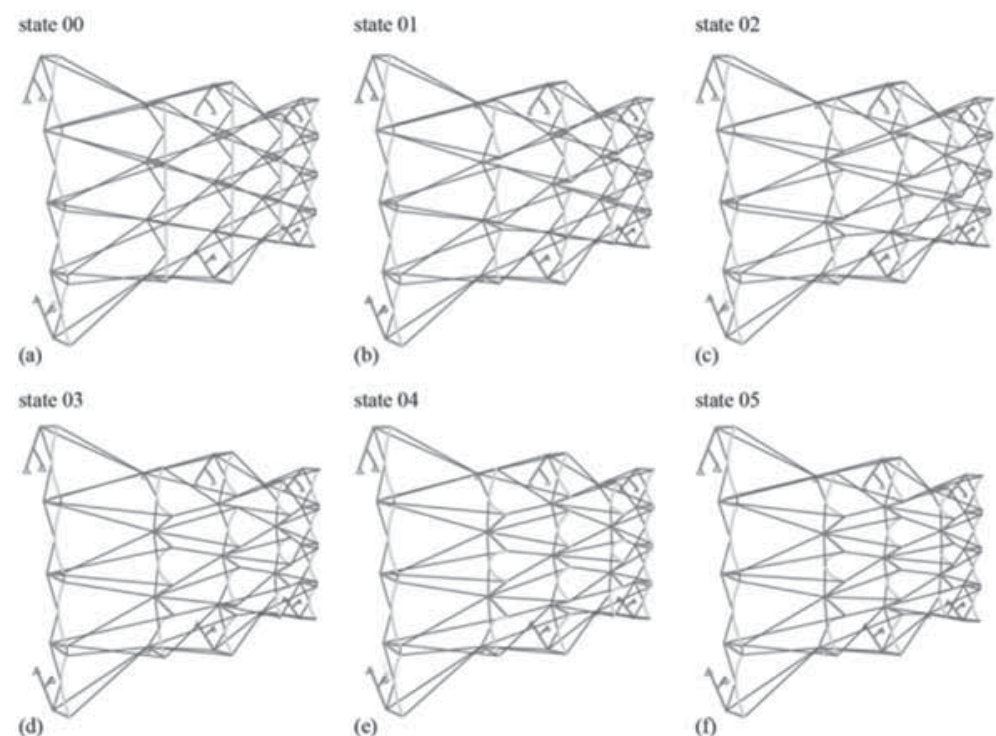

(b)

(c)
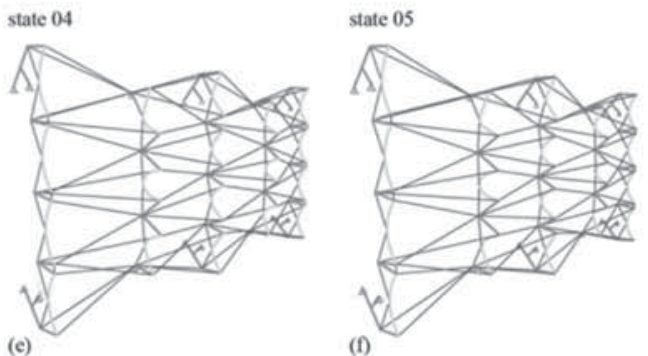

Figure 8: Static system in initial configuration (a) and transformation states 1-5 (b-f).

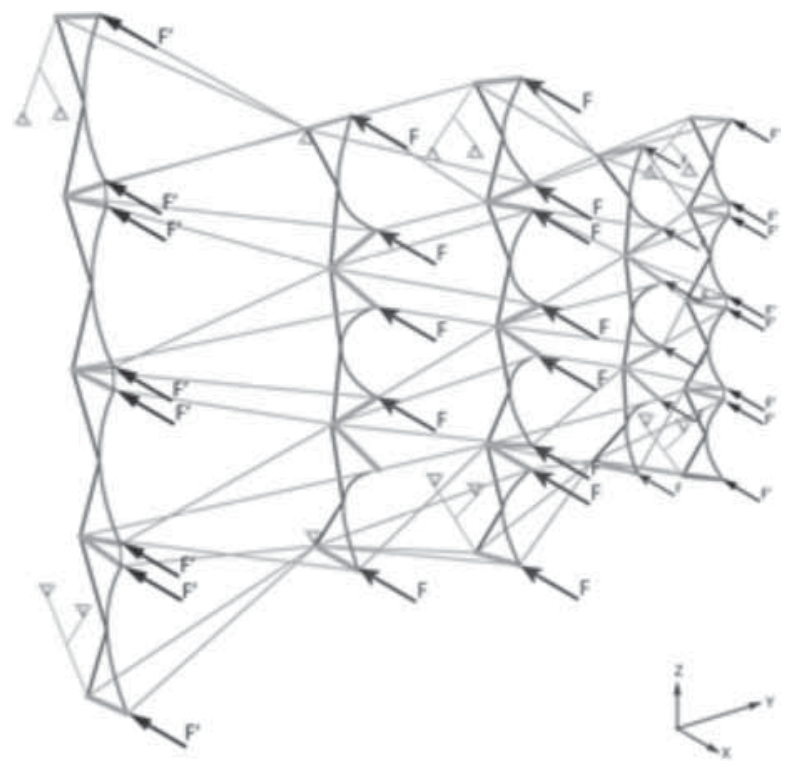

Figure 9: Static system with horizontal loading in a transformation state; $F^{\prime}=0.58 \mathrm{kN}, \mathrm{F}=1.16 \mathrm{kN}$. 
Table 2: Maximum absolute response values under horizontal loading.

\begin{tabular}{lccccccc}
\hline \multirow{2}{*}{ Structural member } & \multirow{2}{*}{$\begin{array}{c}\text { Response value } \\
(\mathrm{kN}, \mathrm{kNm}, \mathrm{cm})\end{array}$} & \multicolumn{7}{c}{ State } \\
\cline { 4 - 8 } & $\mathrm{N}$ & 9.24 & 8.02 & 8.12 & 8.37 & 7.97 & 8.08 \\
\hline Bending members & $\mathrm{M}_{3-3}$ & 0.03 & 0.26 & 0.32 & 0.33 & 0.28 & 0.37 \\
& $\mathrm{~N}$ & 10.49 & 3.97 & 3.98 & 3.94 & 3.83 & 3.93 \\
Compression members & $\mathrm{N}$ & 1.05 & 8.18 & 8.29 & 8.55 & 8.13 & 8.23 \\
Primary cables & $\mathrm{N}$ & 17.20 & 5.50 & 4.65 & 3.38 & 1.58 & 3.96 \\
Secondary cables & $\mathrm{N}$ & 1.54 & 4.93 & 4.90 & 5.03 & 4.93 & 5.00 \\
Support members & $\mathrm{U}_{1-1}$ & 0.53 & 4.08 & 4.56 & 5.21 & 5.09 & 4.86 \\
System joints & $\mathrm{U}_{3-3}$ & 0.13 & 1.21 & 1.45 & 1.40 & 1.50 & 1.84 \\
& & & & & & &
\end{tabular}

respective value of the primary cables (Fig. 10). On the other side in the transformation states with minimum and maximum values of the tension forces developed, i.e. in the fourth transformation state for the secondary cables and third transformation state for the primary cables, the respective ratio amounts to $18.54 \%$. The axial forces developed in the bending-active members indicate a descending progression throughout the transformation pathway of the system, from the initial configuration to the target transformation state, except the respective maximum values in the third transformation state. The maximum deviation of the axial loads of the members amounts to $13.68 \%$, between the initial configuration and the fourth transformation state. Within the transformation states of the system, the respective maximum response deviation amounts to $4.73 \%$, between the third and fourth transformation state. The maximum reaction forces at the primary structure supports have minimum values in the initial configuration state. A relative increase of $226.06 \%$ between the initial configuration and the third transformation state applies practically in all remaining transformation states of the system.

An ascending progression of the maximum bending moments in the perpendicular plane direction of the bending-active members is registered with an increase in the transformation states of the system. The overall increase ratio between the initial configuration and the target transformation state amounts to $1228.57 \%$. Furthermore, no significant torsions in the members' joints have been developed under the symmetrical horizontal loading applied. The respective maximum response value amounts to $0.33 \mathrm{kNm}$, developed in the third transformation state of the system.

The maximum deformations of the system in the main perpendicular plane direction, $\mathrm{U}_{1-1}$, are minimum in the initial configuration state. They follow an ascending progression with a maximum value in the third transformation state (Fig. 11). The respective increase amounts to $889.92 \%$. A maximum deformation value of $5.21 \mathrm{~cm}$ registered in the case study equals to $1.5 \%$ of the storey height. Secondary insignificant deformations have also been registered in the vertical plane direction, $\mathrm{U}_{3-3}$, attributed to the flexural elasticity of the bending-active members.

In principle, the preliminary analysis for the horizontal wind loading case shows that the structural behaviour of the system differs between its initial configuration state with practically ineffective bending-active members and its transformation states. As far as the axial forces of the primary members are concerned, i.e. bending-active and scissor compression members, these decrease substantially 

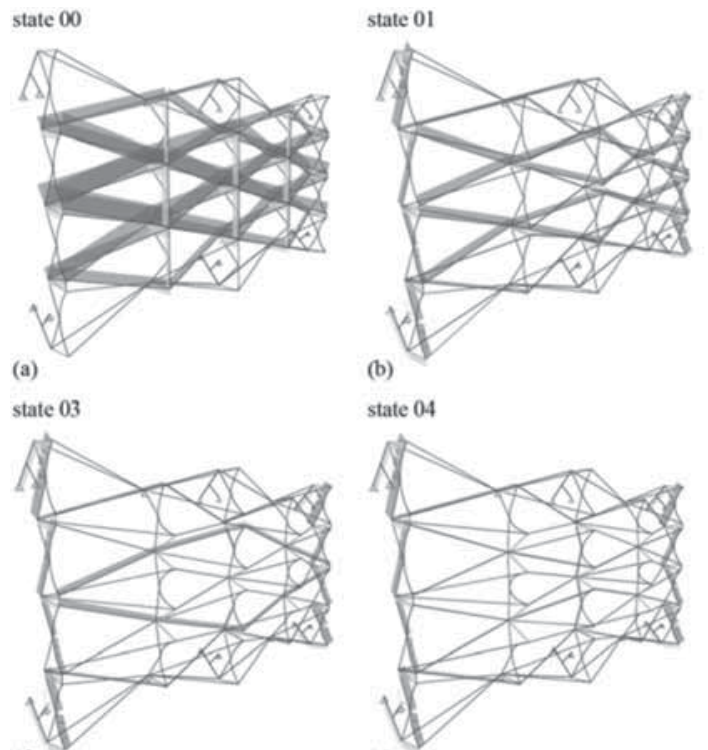

(b)

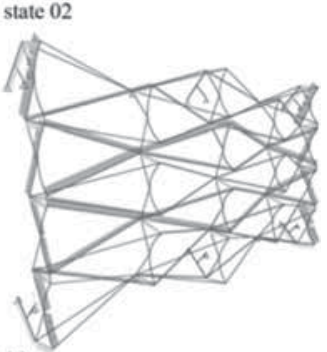

state 04

(c)

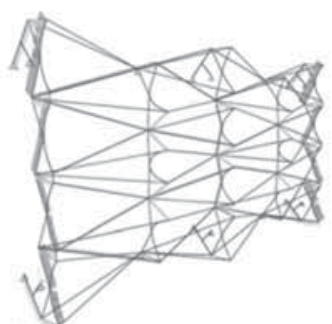

state 05

(e)

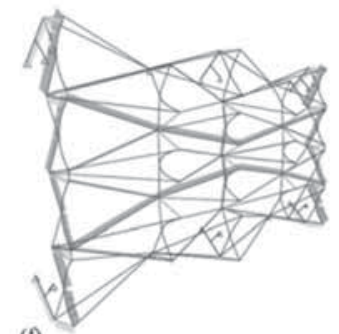

(f)

Figure 10: Static system's axial force diagram in initial configuration (a) and transformation states $1-5(b-f)$.

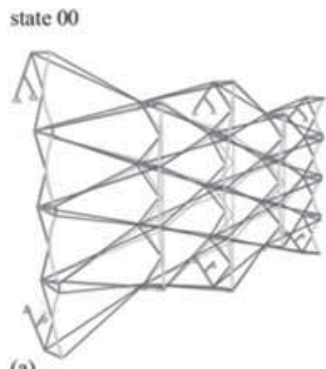

(a)

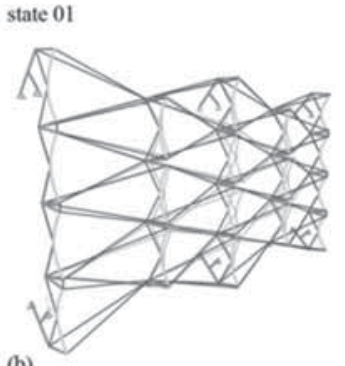

(b)

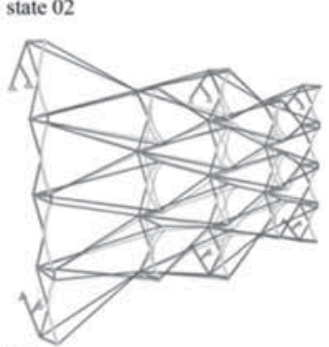

state 03

state 04

state 05
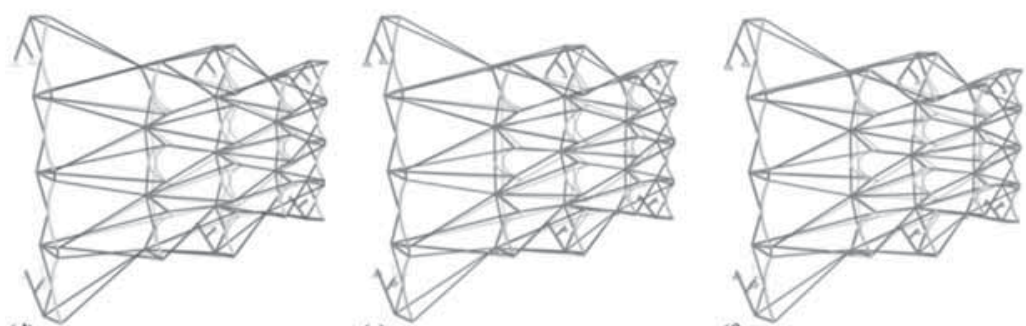

(e)

(1)

Figure 11: Static system's deformation shapes in initial configuration (a) and transformation states 1-5 (b-f). 
within the transformation pathway of the system. In parallel, the activation of the bending-active members throughout the transformation states induces an increase of their bending moments in the perpendicular plane direction. The bracings develop a sharing behaviour with regard to the transformation states investigated. While in the initial configuration state, major part of the tension forces is developed in the secondary cables, with increase in the transformation states of the system, the primary cables are increasingly responsible for the stability of the system. The maximum deformations of the system verify the relative high flexibility of the hybrid structure. On the long run most significant in the horizontal system's behaviour are the maximum deformations within the transformation states that in all cases are held under a limit of $1.5 \%$ of the storey height.

\section{CONTROL SYSTEM}

Each chain of compression members, stabilized through the bending-active members and the primary cables with closed circuit, obtains through modification of the cables' length different geometries that define different configuration states. An integrated active control system is responsible for initiation of different transformation states of the system. The control system of the prototype structure is sought in the fields of robotics, where well-established techniques are used for the kinematic analysis and control of multi-body articulated systems. Therefore, robotics may provide a framework for its analysis and control realization. From a control perspective, performing shape adjustments requires an appropriate control system, with actuators, feedback sensors, as well as suitable motion planning and control algorithms. As the reconfiguration motions shall make efficient use of resources, such as drive power, implementation of optimal control also becomes relevant. Robotically adjustable structures, where not only the configuration but also the actual morphology of the system can change, were discussed in $[60,61]$.

The complete control of the motion of any, for example, planar multi-bar linkage would require at first place equal number of actuators to be installed. However, installing many actuators on the system increases the overall structure's weight, structural deformations and cost. Moreover, operation becomes energy inefficient given that the system will have to move about its own massive components. To avoid the aforementioned issues, a single motion actuator, e.g. electric motor, is implemented for each primary structure with an appropriate motion control approach applied. The actuators are placed on the supports of the primary structures, at the primary cables joints. In addition, electromagnetic brakes, corresponding to each one of the rest of the rotating shafts of the cables, are implemented.

In principle, the control system manages the operation of the motion actuators and the brakes through appropriately planned sequences in order to realize the required shape adjustments. By selectively unlocking only four joints of each primary structure at a time, the mechanism is reduced to an effective 4-bar (E4B) mechanism that has a single degree of freedom in plane. Therefore, a group of consecutive locked joints formulate an 'effective link'. Using the available actuator, any one angle of the E4B linkage, defined through the curvature of the bending-active members and the respective opening angle of the scissor compression members, can be adjusted to its desired value and from then on it will remain locked. For each successive step of the control sequence, a different E4B linkage may be defined and one angle will be adjusted. In general, the process of reconfiguring the overall structure must ensure a synchronous adjustment of the involved linkages with regard to external constraints and the limitation of stresses on the structural members, as well as the corresponding release of kinetic energy accumulated in the elastic bending members in the case of reverse transformation. Once an initial and a target transformation state are defined, the intermediate postures to be assumed will depend on the specifics of the motion pattern. Normally, various possibilities will exist for defining motion patterns and an optimal one may be selected among them on the basis 
of specific criteria, e.g. required actuator forces. For implementing the control concept a single position sensor installed on the actuated joint of each primary structure will suffice, e.g. an optical encoder or a potentiometer. In such a case, the position of the rest of the joints can be inferred through the kinematics solution. However, a more accurate, reliable and practical option is to have position sensors installed on every joint of the multi-bar linkages.

\section{CONCLUSIONS}

Following an integrated iterative process, the design concept of a new kinetic form-active hybrid structure has been presented in the current paper. Based on relevant aspects of material effective structures and autonomous adaptation to external conditions, the specific case design is primarily characterized by an integration of the inherent materials and members' composition to achieve a high system's form flexibility. Inspired by the principle integral characteristic of natural systems and kinematic mechanisms in biology, the design concept is primarily based on the bending-active and scissor principles and further developed into a hybrid structure with controlled stability and kinematic properties. The preliminary investigation of the horizontal structural behaviour of the hybrid system verifies its form flexibility according to possible different operational configuration states of the building envelope. Sensors and a minimum number of actuators are proposed to be integrated within the structure for the kinematics control. In real terms, the determination of the boundary conditions with regard to possible external stimuli comprises the basis for the subsequent interactive development of the structure and the control system.

\section{REFERENCES}

[1] Galilei, G., Dialogues Concerning Two New Sciences, MacMillan Company: Chicago, 1914.

[2] Knippers, J. \& Speck, T., Design and construction principles in nature and architecture. Bioinspiration \& Biomimetics, 7, 2012. Online: http://stacks.iop.org/BB/7/015002. doi: http:// dx.doi.org/10.1088/1748-3182/7/1/015002

[3] Brown, G., Introduction to Transportable Environments 2, ed. R. Kronenburg, Spon Press: London, 2003.

[4] Zuk, W. \& Clark, R.H., Kinetic Architecture, Van Nostrand Reinhold Company: New York, 1970.

[5] Krausse, J. \& Lichtenstein, C. (eds), Your Private Sky. R. Buckminster Fuller Design als Kunst einer Wissenschaft, Lars Mueller: Baden, 2000.

[6] Kronenburg, R. (ed.), Transportable Environments: International Conference on Portable Architecture, E\&FN Spon: London, 1997.

[7] Pugh, A., An Introduction to Tensegrity, University of California Press: Berkeley, 1976.

[8] Motro, R., Tensegrity systems and geodesic domes. Space Structures, 5(3-4), pp. 341-351, 1990.

[9] Pellegrino, S., A class of tensegrity domes. Space Structures, 5(2), pp. 127-142, 1992.

[10] Motro, R., Structural morphology of tensegrity systems. Space Structures, 11(1-2), pp. 25-32, 1996.

[11] Snelson, K., Continuous tension, discontinuous compression structures. US Patent No. 3,169,611, February 16, 1965.

[12] Motro, R., Tensegrity: Structural Systems for the Future. Kogan Page Science: London, 2003.

[13] Connelly, R. \& Terrell, M., Globally rigid symmetric tensegrities. Structural Typology, 21, pp. 59-78, 1995.

[14] Vassart,N.\&Motro,R., Multiparametered formfinding method:application to tensegrity systems. Space Structures, 14(2), pp. 147-154, 1999. doi: http://dx.doi.org/10.1260/0266351991494768 
[15] Zhang, L., Maurin, B. \& Motro, R., Form-finding of nonregular tensegrity systems. Structural Engineering, 132(9), pp. 1435-1440, 2006. doi: http://dx.doi.org/10.1061/(ASCE)07339445(2006)132:9(1435)

[16] Tilbert, A.G. \& Pellegrino, S., Review of form-finding methods for tensegrity structures. Space Structures, 18(4), pp. 209-223, 2003. doi: http://dx.doi.org/10.1260/026635103322987940

[17] Robbin, J.L., Engineering a New Architecture, Yale University Press: New York, pp. 25-37, 1996.

[18] Djouadi, A., Motro, R., Pons, J.C. \& Crosnier, B., Active control of tensegrity systems. Aerospace Engineering, 11, pp. 37-44, 1998. doi: http://dx.doi.org/10.1061/(ASCE)08931321(1998)11:2(37)

[19] Hanaor, A., Geometrically rigid double-layer tensegrity grids. Space Structures, 9(4), pp. 227-238, 1994.

[20] Wang, B. \& Liu, X., Integral-tension research in double-layer tensegrity grids. Space Structures, 11, pp. 349-355, 1996.

[21] Wang, B., Cable-strut systems: Part I - Tensegrity. Construction Steel Research, 45, pp. 281-289, 1998. doi: http://dx.doi.org/10.1016/S0143-974X(97)00075-8

[22] Wang, B., Cable-strut systems: Part II - Tensegrity. Construction Steel Research, 45, pp. 291-299, 1998. doi: http://dx.doi.org/10.1016/S0143-974X(97)00076-X

[23] Kawaguchi, K. \& Lu, Z.-Y., Construction of three-strut tension systems. Proc. of 5th International Conference on Space Structures, pp. 1-10, 2002.

[24] Pellegrino, S. (ed.), Deployable Structures. International Center for Mechanical Sciences, CISM Courses and Lectures No. 412, Springer: New York, 2001.

[25] Gantes, C.J., Deployable Structures: Analysis and Design, WIT Press: Boston, 2001.

[26] Hanaor, A., Tensegrity. Theory and application. Beyond the Cube, ed. G.J. Francois, John Wiley \& Sons: New York, pp. 385-405, 1998.

[27] Tilbert, G., Deployable Tensegrity Structures for Space Applications. Ph.D. Thesis, Royal Institute of Technology, Stockholm, 2002.

[28] Motro, R., Bouderbala, M., Lesaux, C. \& Cevaer, F., Foldable Tensegrities, Deployable Structures, Springer: Wien, pp. 199-238, 2001.doi: http://dx.doi.org/10.1007/978-3-7091-2584-7 11

[29] Gantes, C.J., Connor, J.J., Logcher, R.D. \& Rosenfeld, Y., Structural analysis and design of deployable structures. Computers \& Structures, 32, pp. 661-669, 1989. doi: http://dx.doi. org/10.1016/0045-7949(89)90354-4

[30] Celladine, C. \& Pellegrino, S., First-order infinitesimal mechanism. Solid Structures, 27, pp. 505-515, 1991. doi: http://dx.doi.org/10.1016/0020-7683(91)90137-5

[31] Tibbalds, B., Guest, S. \& Pellegrino, S., Folding Concept for Flexible Surface Reflectors. Publication No. AIAA-98-183, American Institute of Aeronautics and Astronautics, Reston, Virginia, 1998.

[32] Kawaguchi, K., Hangai, Y., Pellegrino, S. \& Furuya, H., Shape and stress control analysis of prestressed truss structures. Reinforced Plastics and Composites, 15, pp. 1226-1236, 1996.

[33] Pinero, E.P., Project for mobile theatre. Architectural Design, 12, pp. 154-155, 1961.

[34] Escrig, F., Expandable space structures. Space Structures, 2(1), pp. 79-91, 1985.

[35] Escrig, F. \& Valcarcel, J.P., Curved expandable space grids. Proc. of International Conference on the Design and Construction of Non-Conventional Structures, London, pp. 157-168, 1987. doi: http://dx.doi.org/10.4203/ccp.7.18.1

[36] Hoberman, C., Unfolding architecture: an object that is identically a structure and a mechanism. Architectural Design, 63, pp. 56-59, 1993. 
[37] You, Z. \& Pellegrino, S., Foldable bar structures. Solids Structures, 15(34), pp. 1825-1847, 1997. doi: http://dx.doi.org/10.1016/S0020-7683(96)00125-4

[38] Akgün, Y., Gantes, C.J., Kalochairetis, K. \& Kiper, G., A novel concept of convertible roofs with high transformability consisting of planar scissor-hinge structures. Engineering Structures, 32, pp. 2873-2883, 2010. doi: http://dx.doi.org/10.1016/j.engstruct.2010.05.006

[39] Akgün, Y., Gantes, C.J., Sobek, W., Korkmaz, K. \& Kalochairetis, K., A novel adaptive spatial scissor-hinge structural mechanism for convertible roofs. Engineering Structures, 33, pp. 1365-1376, 2011. doi: http://dx.doi.org/10.1016/j.engstruct.2011.01.014

[40] Culshaw, B., Smart Structures and Materials, Artech House, Inc.: Boston, 1996.

[41] Sultan, C., Modeling, Design and Control Tensegrity Structures with Applications. Ph.D. Thesis, Purdue University, West Lafayette, Ind., 1999.

[42] Skelton, R.E., Pinaud, J.P. \& Mingori, D.L., Dynamics of the shell class of tensegrity structures. Journal of the Franklin Institute, 338, pp. 255-320, 2001. doi: http://dx.doi.org/10.1016/ $\underline{\text { S0016-0032(00)00078-8 }}$

[43] Fest, E., Shea, K., Domer, B. \& Smith, I.F.C., Adjustable tensegrity structures. Structural Engineering, 129(4), pp. 515-526, 2003. doi: http://dx.doi.org/10.1061/(ASCE)07339445(2003)129:4(515)

[44] Fest, E., Shea, K. \& Smith, I.F.C., Active tensegrity structures. Structural Engineering, 130(10), pp. 1454-1465, 2004. doi: http://dx.doi.org/10.1061/(ASCE)0733-9445(2004)130:10(1454)

[45] Sterk, T.E., Using actuated tensegrity structures to produce a responsive architecture. Connecting Crossroads of Digital Discourse, Proc. of 2003 Annual Conference of the Association for Computer Aided Design in Architecture, ACADIA 22, Indianapolis, pp. 86-93, 2003.

[46] Schlaich, J., Bergermann, R., Boegle, R., Cachola, A. \& Flagge, S. P., Light Structures, Prestel: New York, 2005.

[47] Engel, H., Structure Systems, Hatje Cantz: Stuttgart, 2009.

[48] Schleicher, S., Adaptive façade shading systems inspired by natural elastic kinematics. International Adaptive Architecture Conference, Building Centre, London, 2011.

[49] Lienhard, J., Schleicher, S. \& Knippers, J., Bending-active structures - Research pavilion ICD/ ITKE. Taller Longer Lighter, Proc. of International Symposium of the International Association of Shell and Spatial Structures, eds. D. Nethercote, S. Pellegrino et al., London, 2011.

[50] Fleischmann, M., Knippers, J., Lienhard, J., Menges, A. \& Schleicher, S., Material behavior. Architectural Design, 216, pp. 44-51, 2012. doi: http://dx.doi.org/10.1002/ad.1378

[51] Schinneger, K., Rutzinger, S., Knippers, J. \& Scheible, F., Biomimetic media façade. Thematic pavilion Expo 2012 Yeosu, South Korea. International Adaptive Architecture Conference, Building Centre, London, 2011.

[52] ITKE, Institute of Building Structures and Structural Design (ed.), Flectofin. Hingeless and Continuously Adjustable Flapping Mechanism on the Basis of Biomimetic Principles, University of Stuttgart: Stuttgart, 2011.

[53] Khoo, C.K., Salim, F. \& Burry, J., Designing architectural morphing skins with elastic modular systems. Architectural Computing, 4(9), pp. 397-419, 2011. doi: http://dx.doi. org/10.1260/1478-0771.9.4.397

[54] Schumacher, M., Schaeffer, O. \& Vogt, M.M., Move. Architecture in Motion - Dynamic Components and Elements. Birkhaeuser: Basel, 2010.

[55] Ferre, A., Patent Constructions. New Architecture Made in Catalonia. Actar: Barcelona, 2007.

[56] Nicolaou, N., Add-Active Surface. Responsive Kinetic Architectural Systems. Department of Architecture, University of Cyprus: Nicosia, 2012. 
[57] Fleischmann, M. \& Menges, A., Physics-based modeling as an alternative approach to geometrical constrain-modeling for the design of elastically-deformable material systems. Proc. of 30th eCAADe Conference, eCAADe 2012, Digital Physicality, eds. H. Achten, J. Pavlicek, J. Hulin, D. Matejovska, eCAADe and CVUT: Prague, Vol. 1, pp. 565-575, 2012.

[58] Ahlquist S. \& Menges, A., Realizing formal and functional complexity for structurally dynamic systems in rapid computational means: computational methodology based on particle systems for complex tension-active form generation. Advances in Architectural Geometry 2010, eds. C. Ceccato, L. Hesselgren, M. Pauly, H. Pottmann \& J. Wallner, Springer: Vienna, pp. 205-220, 2011.

[59] Phocas, M.C., Kontovourkis, O. \& Ioannou, T., Interdisciplinary research based design: the case of a kinetic form-active tensile membrane. Architectural Engineering Technology, 1(2), 2012. doi: http://dx.doi.org/10.4172/2168-9717.1000104

[60] Hjelle, D. \& Lipson, H., A robotically reconfigurable truss. Proc. of 2009 International Conference on Reconfigurable Mechanisms and Robots, IEEE, London, 2009.

[61] Sultan, C., Tensegrity: 60 years of art, science and engineering. Advances in Applied Mechanics, 43, pp. 69-145, 2009. doi: http://dx.doi.org/10.1016/S0065-2156(09)43002-3 